\title{
A Review of Studies in Structural Health Monitoring (SHM)
}

\author{
Saurav Dixit ${ }^{\text {a*}}$, Kaaraayaarthi Sharma ${ }^{\mathrm{a}}$ \\ ${ }^{a}$ RICS School of Built Environment, Amity University Noida, 201313, India
}

\begin{abstract}
India is a country of diversity not only in terms of culture and population but also in terms of landscape ranging from snow-capped mountains to desserts, plateaus, plains and hills. The climatic conditions in India vary from extremely hot to extremely cold resulting in the requirement of different types of constructions in each region subjected to its temperature, geographical and climate conditions. India is a county where thousands of years old buildings are still standing strong despite several changes in various factors over the years, whereas a few years old building collapses more easily, which raises the most important question in our mind regarding the Structural health of buildings over the years and how Well structure health monitoring is done in India. Structural Health Monitoring is defined as a process of identification of damage for aerospace, mechanical and civil infrastructure. Performance of the structures are determined by various factors such as the age of the building, material used, service condition and layout of the structure besides performance, safety, reliability and serviceability are also the crucial points. SHM technology is implemented in various countries like Europe, USA, Korea, Japan etc. for monitoring of large structures. The main aim behind the implementation of SHM is to determine the damage during initiation itself so that the further damage propagation can be ceased by an alarm in the initial stage with the help of continuous monitoring by structurally integrated sensors.
\end{abstract}

(C) 2019 The Authors. Published by Budapest University of Technology and Economics \& Diamond Congress Ltd.

Peer-review under responsibility of the scientific committee of the Creative Construction Conference 2019.

Keywords: SHM; Building Construction; Technology; India; Construction Management; Building Material.

\section{Introduction}

Over the years construction industry has observed a huge change in the methods adopted for the construction. From the use of natural materials for construction to the use of composite materials for specific construction, Construction industry has seen a continuous trend of simple to complex construction. After completion of the construction these structures are exposed to various conditions resulting in its deterioration. Every structure deteriorate with the passage of time. There are various reasons due to which structure deteriorates for example repetitive traffic load, any natural calamity etc., which in turn reduces the margin of safety and the serviceability span of the structure resulting in the loss of life and structure. The main aim of SHM is to give the diagnosis of the state, at every movement of the life cycle of the structure. The process of implementation of the strategy to detect the damage is known as Structural Health Monitoring (SHM). SHM is used for rapid condition screening and aims to provide, in near real time, reliable information regarding the integrity of the structure.

\subsection{SHM}

\section{Health Monitoring}

*Corresponding author: Author email: sdixit@ricssbe.edu.in 
Dixit, Sharma/ Proceedings of the Creative Construction Conference (2019) 013

https://doi.org/10.3311/CCC2019-013
II. Operational Evaluation
III. Data Feature Extraction
IV. Statistical Models Development

First and the foremost step of SHM is to identify the damage, then determine the geometric location of the damage, after that quantification of damage severity is done and lastly the remaining life of the structure is predicted. Following are the objectives of the SHM:-

I. How to improve the performance of the existing structure.

II. Monitoring of structures affected by external factors.

III. To provide feedback in order to improve the design for future.

IV. Assessment of structural integrity after the earthquake.

When the structure is embedded with the sensors for the monitoring it is called as Passive SHM and when the structure is embedded with sensors as well as actuators in order to generate perturbations in the structure, to see its response it is called as Active SHM. Following are the SHM techniques:-
I. Vibration based technique
II. Fibre - Optic Sensors
III. SHM with Piezoelectric Sensors
IV. SHM using Electrical Resistance
V. Low Frequency Electromagnetic Techniques
VI. Capacitive Methods for SHM in Civil Engineering

Damage can be identified by two ways which are Global and Local. When the whole structure is assessed simultaneously it is known as Global Damage Detection. And when the non-destructive evaluation tool focus on a specific component of a structure it is called as Local Damage Detection.

\section{Literature review}

[1] Provide one of the most comprehensive reviews of the technical literature concerning the detection, location, and characterization of structural damage through techniques that examine changes in measured structural-vibration response. [2] Talks about the limitations associated with the SHM. According to them to identify the damage on the basis of realistic data set is far away from the reality with robust identification technique. [3]cite some critical issues for SHM, particularly with civil infrastructure, which need to be resolved for deploying reliable SHM systems. According to the Author combination of integrated approach, between government, academia and industry is required, and engineering approach irrespective of the engineering branch is needed to sort out the issues related to SHM. The author focuses on the following requirements to improve SHM:-

a. Organizations which can improve the integration of performance of the structures with the design.

b. Need for standards that govern sensor calibration and documentation of stochastic information regarding the measurement of certain environmental parameters.

c. Need for standards which would be valid in case of retrofitting structures to make sure that the retrofitting achieve its goal of strengthening the structure. 
Dixit, Sharma/ Proceedings of the Creative Construction Conference (2019) 013

https://doi.org/10.3311/CCC2019-013

[4], [5] question whether only one damage-sensitive feature or a vector of various features is suitable for practical SHM systems. The author refer to the various causes of the damage and the inherent non stationarity of those causes suggest that both local and global approaches to SHM must be investigated simultaneously [6]-[9]. According to [10], the engineering structural health concept encompasses four distinct subsets:
a. Sensor allocation and measurements,
b. Structural identification,
c. Damage or degradation detection, and
d. Decision-making.

Damage identification methods can also be classified as "model-based method" or "response-based method"[11].

The model-based method assumes that a detailed numerical model of the structure is available for damage identification; while the response-based method depends only on experimental response data from structures[12], [13]. According to [9] the various considerations which influence the choice and effectiveness of SHM methods are:-

a. What is the level of damage and deterioration related to it,

b. The types of sensors used,

c. The degree of measurement noise pollution, and

d. The level of prior information about the condition of the structure, etc.

Structures are generally rated and monitored once a year or once in several years according to the importance and the age of the structure

Table 1previous studies in SHM

\begin{tabular}{|l|l|}
\hline Authors & Findings \\
\hline$[14]$ & $\begin{array}{l}\text { proposed a novel health indicator extraction method based on the available } \\
\text { sensor parameters for the health monitoring of Air Conditioning System } \\
\text { (ACS) of a legacy commercial aircraft model }\end{array}$ \\
\hline$[15]$ & $\begin{array}{l}\text { Monitoring the parameters including temperature, humidity, pH, corrosion } \\
\text { rate, and stress/strain and the sensors particularly fabricated based on fiber } \\
\text { optic, Bragg grating, piezoelectric, electrochemical, wireless and self-sensing } \\
\text { technologies. }\end{array}$ \\
\hline$[7]$ & $\begin{array}{l}\text { The effect of varying environment needs to be considered and eliminated } \\
\text { while conducting structural health monitoring. }\end{array}$ \\
\hline$[3]$ & $\begin{array}{l}\text { It provides useful tools for processing and analyzing these big machinery data } \\
\text { "Describing the design, suggesting improvements in the V-notch sensors, } \\
\text { evaluating stresses to predict the failure of critical components (such as bridge } \\
\text { ways) by using ANSYS simulations to estimate the stresses through V-notch } \\
\text { geometry passive sensors with different depths in the structure". }\end{array}$ \\
\hline$[16]$ & $\begin{array}{l}\text { Due to the complex behavior of mooring lines, a new design of Radial Basis } \\
\text { Function (RBF) neural network is proposed for damage diagnosis. }\end{array}$ \\
\hline$[8]$ & $\begin{array}{l}\text { The authors presents an original approach to structural health monitoring of } \\
\text { helicopter rotors based on strain measurement on the blades }\end{array}$ \\
\hline$[17]$ &
\end{tabular}


Dixit, Sharma/ Proceedings of the Creative Construction Conference (2019) 013

https://doi.org/10.3311/CCC2019-013

\begin{tabular}{|l|l|}
\hline$[12]$ & $\begin{array}{l}\text { This paper deals with assessing the integrity of composite structures via modal } \\
\text { acoustic emission (MAE) technique. }\end{array}$ \\
\hline$[13]$ & $\begin{array}{l}\text { Non-destructive testing (NDT) techniques play an important monitoring } \\
\text { (SHM) of composite structures, among which infrared thermography (IRT). }\end{array}$ \\
\hline$[9]$ & $\begin{array}{l}\text { A novel framework to fuse structural health monitoring (SHM) data from } \\
\text { different in-situ monitoring techniques is proposed aiming to develop a hyper- } \\
\text { feature towards more effective prognostics. }\end{array}$ \\
\hline$[18]$ & $\begin{array}{l}\text { The authors discussed the review of structures with structural health } \\
\text { monitoring system. }\end{array}$ \\
\hline$[4]$ & $\begin{array}{l}\text { presents a system that monitors the health of structural elements in Reinforced } \\
\text { Concrete }\end{array}$ \\
\hline
\end{tabular}

\section{Discussion}

NDE techniques, which are commonly used for localized evaluation of large structures, fails when used for complete evaluation of the global and local performance of the structure. To examine the changes in the static and/or dynamic characteristics of the structure while monitoring their dynamic and/or static responses gives rise to the need of the development of the additional global damage detection methods which can be applied to the complex structures as well. The response-based techniques have the potential to evaluate the whole structure due to its simple setup and potential automation of data acquisition, data processing, and defect detection, [5], [10], [18]. Performance of the structures are determined by various factors such as the age of the building, material used, service condition and layout of the structure besides performance, safety, reliability and serviceability are also the crucial points. SHM technology is implemented in various countries like Europe, USA, Korea, Japan etc. for monitoring of large structures [4], [5], [7], [10], [13], [16]-[18] [19]-[21]. The main aim behind the implementation of SHM is to determine the damage during initiation itself so that the further damage propagation can be ceased by an alarm in the initial stage with the help of continuous monitoring by structurally integrated sensors.

\section{References}

[1] "IMPROVING QUALITY IN THE BUILT."

[2] K. Roy, "Structural Health Monitoring,” no. June, 2016.

[3] R. Zhao, R. Yan, Z. Chen, K. Mao, P. Wang, and R. X. Gao, "Deep learning and its applications to machine health monitoring," Mech. Syst. Signal Process., vol. 115, pp. 213-237, 2019. https://doi.org/10.1016/j.ymssp.2018.05.050

[4] Y. Bao, Z. Chen, S. Wei, Y. Xu, Z. Tang, and H. Li, "The State of the Art of Data Science and Engineering in Structural Health Monitoring," Engineering, 2019. https://doi.org/10.1016/j.eng.2018.11.027

[5] S. Villalba and J. R. Casas, "Application of optical fiber distributed sensing to health monitoring of concrete structures," Mech. Syst. Signal Process., vol. 39, no. 1-2, pp. 441-451, 2013. https://doi.org/10.1016/j.ymssp.2012.01.027

[6] “A Review of Structural Health Monitoring Literature : 1996 - 2001,” pp. 1996-2001, 2001.

[7] X. Zhao and Z. Lang, "Baseline model based structural health monitoring method under varying environment," Renew. Energy, vol. 138, pp. 1166-1175, 2019. https://doi.org/10.1016/j.renene.2019.02.007

[8] H. Rezaniaiee Aqdam, M. M. Ettefagh, and R. Hassannejad, "Health monitoring of mooring lines in floating structures using artificial neural networks," Ocean Eng., vol. 164, no. July 2017, pp. 284-297, 2018. https://doi.org/10.1016/j.oceaneng.2018.06.056

[9] P. Klikowicz, M. Salamak, and G. Poprawa, "Structural Health Monitoring of Urban Structures," Procedia Eng., vol. 161, pp. 958962, 2016. https://doi.org/10.1016/j.proeng.2016.08.833

[10] J. Y. Wu, S. Sfarra, and Y. Yao, "Sparse Principal Component Thermography for Structural Health Monitoring of Composite Structures," IFAC-PapersOnLine, vol. 51, no. 24, pp. 855-860, 2018. https://doi.org/10.1016/j.ifacol.2018.09.675

[11] M. A. Abdo, Structural Health Monitoring History, Applications and Future Mohamed Abdel-Basset Abdo Open Science, no. January 2014. 2015.

[12] S. Yaacoubi, F. Dahmene, A. Bouzenad, M. El Mountassir, and M. Aouini, "Modal acoustic emission for composite structures health monitoring: Issues to save computing time and algorithmic implementation," Compos. Struct., vol. 183, no. 1, pp. 338-346, 2017. https://doi.org/10.1016/j.compstruct.2017.03.081

[13] N. Eleftheroglou, D. Zarouchas, T. Loutas, R. Alderliesten, and R. Benedictus, "Structural health monitoring data fusion for in-situ life https://doi.org/10.1016/j.ress.2018.04.031 
Dixit, Sharma/ Proceedings of the Creative Construction Conference (2019) 013

https://doi.org/10.3311/CCC2019-013

prognosis of composite structures," Reliab. Eng. Syst. Saf., vol. 178, no. June 2017, pp. 40-54, 2018.

[14] J. SUN, C. LI, C. LIU, Z. GONG, and R. WANG, “A data-driven health indicator extraction method for aircraft air conditioning system health monitoring," Chinese J. Aeronaut., vol. 32, no. 2, pp. 409-416, 2019.

[15] S. Taheri, “A review on five key sensors for monitoring of concrete structures," Constr. Build. Mater., vol. 204, pp. 492-509, 2019.

[16] A. Hadyia and A. Güngör, "Fatigue v-notch sensor for monitoring the health of critical structures,” Eng. Sci. Technol. an Int. J., vol. 22, no. 2, pp. 391-398, 2018.

[17] J. Serafini, G. Bernardini, R. Porcelli, and P. Masarati, "In-flight health monitoring of helicopter blades via differential analysis," Aerosp. Sci. Technol., vol. 88, pp. 436-443, 2019.

[18] C. Ayyildiz et al., "Structure health monitoring using wireless sensor networks on structural elements," Ad Hoc Networks, vol. 82, pp. 68-76, 2019.

[19] S. Dixit, S. N. Mandal, J. V. Thanikal, and K. Saurabh, "Evolution of studies in construction productivity: A systematic literature review (2006-2017)," Ain Shams Eng. J., no. xxxx, 2019.

[20] S. Dixit, S. N. Mandal, J. V Thanikal, and K. Saurabh, "Critical Analysis of Factors Affecting the on-site Productivity in Indian Construction Industry," no. July, pp. 38-45, 2018.

[21] S. Dixit, S. N. Mandal, J. V Thanikal, and K. Saurabh, "Construction Productivity and Construction Project Performance in Indian Construction Projects," vol. m, no. July, pp. 379-386, 2018. 